\title{
DESEMPENHO ECONÔMICO-FINANCEIRO E DESEMPENHO ESPORTIVO: UMA ANÁLISE COM CLUBES DE FUTEBOL DO BRASIL
}

\author{
ECONOMIC-FINANCIAL PERFORMANCE AND SPORTIVE \\ PERFORMANCE: AN ANALYSIS WITH FOOTBALL CLUBS IN \\ BRAZIL
}

\section{DESEMPEÑO ECONÓMICO-FINANCIERO Y DESEMPEÑO DEPORTIVO: UN ANÁLISIS CON CLUBES DE FÚTBOL DE BRASIL}

\author{
Hugo Lucindo Ferreira \\ Mestre em Ciências Contábeis - Universidade \\ Federal do Rio de Janeiro, Rio de Janeiro, Brasil \\ Professor substituto - Universidade Federal de \\ Alfenas, Varginha, Brasil \\ hugolucindo@gmail.com \\ José Augusto Veiga da Costa Marques \\ Pós-Doutor em Controladoria e Contabilidade - \\ Universidade de São Paulo, São Paulo, Brasil \\ Professor associado - Universidade Federal do \\ Rio de Janeiro, Rio de Janeiro, Brasil \\ joselaura@uol.com.br
}

\section{Marcelo Alvaro da Silva Macedo}

Pós-Doutor em Controladoria e Contabilidade Universidade de São Paulo, São Paulo, Brasil

Professor adjunto - Universidade Federal do Rio de Janeiro, Rio de Janeiro, Brasil

malvaro@facc.ufrj.br

\author{
Contextus \\ ISSN 1678-2089 \\ ISSNe 2178-9258 \\ Organização: Comitê Científico Interinstitucional \\ Editor Científico: Diego de Queiroz Machado \\ Editor Executivo: Carlos Daniel Andrade \\ Avaliação: double blind review pelo SEER/OJS \\ Recebido em 09/03/2018 \\ Aceito em 13/07/2018 \\ $2^{a}$ versão aceita em 27/07/2018
}

\begin{abstract}
RESUMO
O estudo tem por objetivo verificar a relação entre os desempenhos esportivo e financeiro dos clubes do futebol brasileiro que disputaram as Séries A ou B ao menos uma vez entre 2013 e 2016. Para medir o desempenho esportivo, foram selecionadas a pontuação dos clubes no Ranking Oficial de Clubes da CBF e a pontuação em um ranking elaborado pelos autores, que utilizou a mesma metodologia do Ranking da CBF, mas considerando apenas o desempenho no ano corrente. Já para o desempenho financeiro, foram utilizados os indicadores: Receita Operacional Bruta, Despesa com Salários, EBIT e Endividamento. Analisou-se a estatística descritiva e de regressão com dados em painel, controlando os efeitos fixos. Os resultados indicaram uma relação positiva e significante de receita bruta, despesa com salários e endividamento com o desempenho esportivo dos clubes. $\mathrm{O}$ EBIT e a dummy ano eleitoral não foram significantes, não apresentando relação com o resultado esportivo dos clubes.
\end{abstract}

Palavras-chave: clubes de futebol; desempenho financeiro; desempenho esportivo; indicadores financeiros; futebol brasileiro. 
year. For the financial performance, the following indicators were used: Gross Operating Revenue, Wage Expenditure, EBIT and Indebtedness. Descriptive statistics analysis and regression with panel data, controlling the fixed effects, were performed. The research findings indicate a positive and significant relationship of gross income, salary expenditure and indebtedness with the clubs' sports performance in the four regression models. EBIT and the dummy of electoral year weren't significant, showing no relation with the clubs' sports results.

Keywords: football clubs; financial performance; sports performance; financial indicators; brazilian football.

\section{RESUMEN}

El estudio tiene por objetivo verificar la relación entre los desempeños deportivo y financiero de los clubes del fútbol brasileño que disputaron por lo menos una vez las series A o B entre 2013 y 2016. Para medir el desempeño deportivo, se seleccionaron la puntuación de los clubes en el Ranking Oficial de Clubes de la CBF y la puntuación en un ranking elaborado por los autores, que utilizó la misma metodología del Ranking de la CBF, pero considerando apenas el desempeño en el año corriente. Para el desempeño financiero, se utilizaron los indicadores: Ingreso Operativo Bruto, Gasto con Salarios, EBIT y Endeudamiento. Se realizó el análisis de la estadística descriptiva y de regresión con datos en panel, controlando los efectos fijos. Los resultados indicaron una relación positiva y significativa de ingresos brutos, gasto en salarios y endeudamiento con el desempeño deportivo de los clubes. El EBIT y la dummy año electoral no fueron significativos, no presentando relación con el resultado deportivo de los clubes.

Palabras-clave: clubes de fútbol; desempeño financiero; desempeño deportivo; indicadores financieros; fútbol brasileño.

\section{INTRODUÇÃO}

O futebol é um dos esportes mais praticados no Brasil e no mundo, atraindo atletas profissionais, amadores e espectadores. Ao longo das últimas décadas, passou por um processo de evolução que levou a mudanças importantes. Deixou de ser visto apenas como esporte e passou a ser considerado um negócio rentável e vantajoso, tornando-se uma grande "indústria do entretenimento", capaz de gerar cifras expressivas, tanto direta quanto indiretamente (HOFFMANN; GING; RAMASAMY, 2002; MÓSCA; SILVA; BASTOS, 2009; KERN; SCHWARZMANN; WIEDENEGGER, 2012; NASCIMENTO et al., 2015).

Essa mudança de tratamento do futebol surgiu no momento em que a televisão começou a exibir os jogos, em transmissões gratuitas ou através de canais por assinatura, dando origem aos patrocinadores, que passaram a anunciar nas placas de publicidades, nos estádios e nos uniformes dos clubes (DANTAS; BOENTE, 2011). Esse processo se beneficiou do fato de esse esporte possuir grande apelo popular, com os torcedores fortemente ligados a seus clubes (REZENDE; DALMÁCIO; PEREIRA, 2010; REZENDE; CUSTÓDIO, 2012).

Nascimento et al. (2015) reconhecem que o futebol exerce um papel social muitíssimo relevante, ao gerar tanto entretenimento, quanto emprego e renda. Assim, a continuidade operacional das entidades esportivas é importante não só para o clube, mas também para a sociedade como um todo. 
O objetivo de um clube de futebol é alcançar o sucesso esportivo, conseguido com vitórias e conquistas de títulos. Paralelamente, uma entidade esportiva, tal qual uma entidade de qualquer outro setor, necessita de equilíbrio financeiro para poder manter-se em operação (ESPITIA-ESCUER; GARCÍA-CEBRIÁN, 2010).

Analisando a literatura atual, é possível verificar a falta de consenso quanto à existência ou não de relação entre os desempenhos financeiro e esportivo. Pesquisas como Szymanski (1998), Dantas, Machado e Macedo (2015) e Ferri et al. (2017) apontam para uma ligação forte e positiva entre ambos os desempenhos. Todavia, autores como Göllü (2012), Pereira et al. (2015) e Benin (2017) concluem não ser possível afirmar a existência da relação.

Diante disso, o presente trabalho objetiva analisar como os resultados econômicos e financeiros se relacionam com o desempenho esportivo dos clubes de futebol das Séries A e B do campeonato brasileiro. O objetivo específico consiste em analisar a situação econômica e financeira dos clubes de futebol no período compreendido entre 2013 e 2016.

A pesquisa se justifica, primeiramente, pelo fato de a combinação de desempenho esportivo com desempenho econômico-financeiro ainda ser um assunto relativamente novo no âmbito acadêmico, ainda não totalmente explorado e apresentando resultados divergentes. Além disso, a temática do futebol é assunto de interesse tanto de torcedores, como de governos, patrocinadores etc. (FIGUEIREDO; SANTOS; CUNHA, 2015), principalmente com esse esporte subindo ao patamar de negócio vantajoso, como já mencionado anteriormente.

Esta pesquisa se distingue das demais em alguns aspectos. Primeiramente pelo método de análise de dados empregado: a regressão, para verificar a relação entre desempenhos financeiros e esportivos. A regressão por dados em painel se mostra como técnica estatística eficiente, melhorando os resultados encontrados por considerar, também, as variações temporais. As variáveis e a composição da amostra também diferem das outras pesquisas com a mesma temática, utilizando clubes da série A e B do Campeonato Brasileiro de 2013 a 2016. O recorte temporal a partir de 2013 já contempla as mudanças ocorridas nos critérios de reconhecimento, mensuração e divulgação das informações contábeis, inseridas pela Resolução CFC n ${ }^{\circ} 1.429$ de 2013.

O restante deste artigo se divide em quatro seções. A segunda apresenta a revisão da literatura nacional e internacional sobre o tema. A terceira seção aborda os aspectos metodológicos do trabalho. Em seguida, apresentam-se a análise e o tratamento dos dados, bem 
como os resultados das correlações e regressões realizadas. Por fim, são expostas as considerações finais, limitações e sugestões de pesquisas futuras.

\section{REVISÃO DA LITERATURA}

\subsection{Desempenho esportivo e desempenho financeiro}

O objetivo de uma entidade esportiva é o sucesso, atingido através de vitórias e conquistas de títulos. Contudo, estes possuem uma meta paralela: a continuidade operacional. Dessa forma, um clube de futebol, assim como uma empresa de qualquer outro setor, necessita ter equilíbrio financeiro para poder manter-se em operação e ser competitivo frente aos seus adversários (ESPITIA-ESCUER; GARCÍA-CEBRIÁN, 2010; FREITAS; FARIAS; FLACH, 2017).

Assim, pode-se dizer que os clubes profissionais de futebol são um tipo de negócio especial, pois precisam alcançar o resultado esportivo e manter um bom desempenho financeiro (GUZMÁN, 2006). Em países onde os clubes de futebol são entidades com fins lucrativos, o desempenho financeiro torna-se um segundo objetivo das equipes. No caso do Brasil, onde os clubes são, em sua grande maioria, entidades sem fins lucrativos, pode-se entender o resultado financeiro como meio para alcançar o bom desempenho esportivo.

Barros, Assaf e Araujo (2011) colocam o objetivo esportivo e desempenho financeiro no mesmo patamar de importância, afirmando que as entidades esportivas competem em duas áreas principais: resultados no campo e boa gestão financeiro. Complementam, ainda, que estes dois conceitos sempre estiveram interligados (BARROS; ASSAF; ARAÚJO, 2011). Para Ferri et al. (2017), os gestores do futebol não precisam necessariamente decidir entre o sucesso esportivo e o desempenho financeiro, pois as duas lógicas podem coexistir.

$\mathrm{Na}$ busca de alcançar simultaneamente a boa gestão financeira e os resultados esportivos, os clubes de futebol acabam entrando em um "círculo vicioso", conforme abordado por Baroncelli e Lago (2006) e apresentado pela Figura 1. 
Figura 1 - Círculo vicioso entre o resultado esportivo e o resultado financeiro

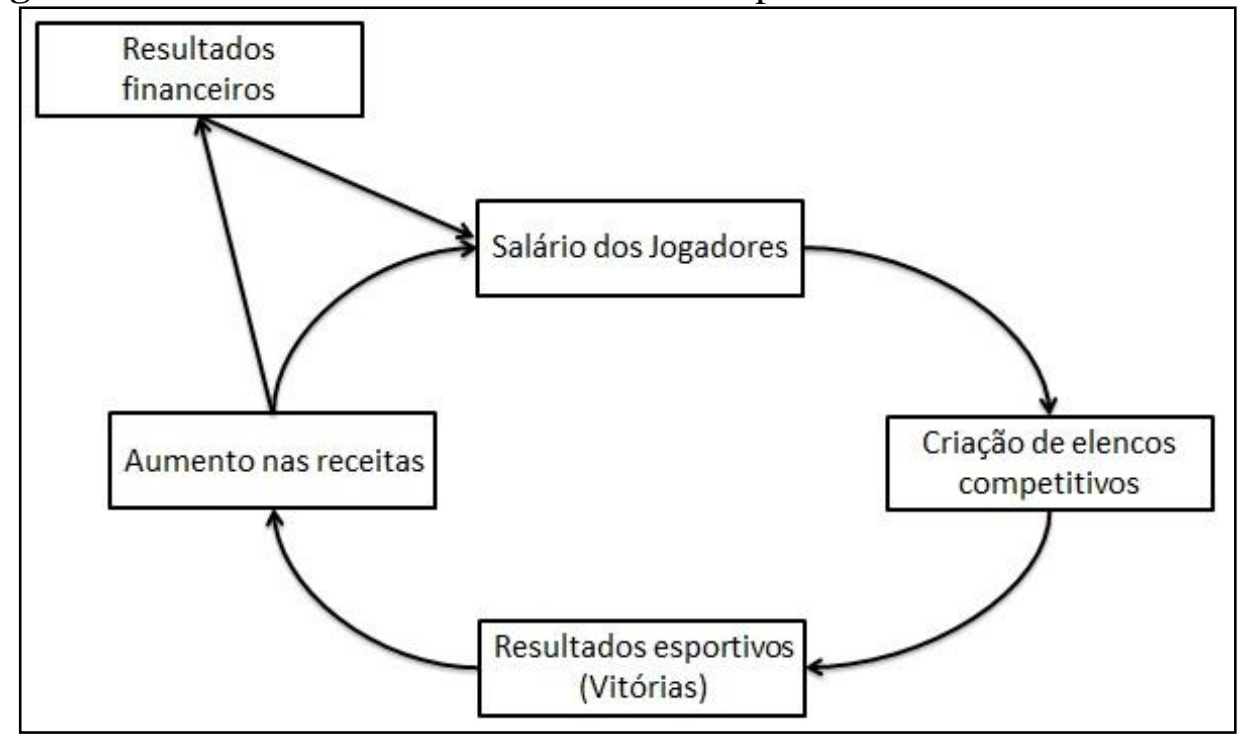

Fonte: adaptado de Baroncelli e Lago (2006).

De acordo com a Figura 1, tem-se inicialmente o investimento em salário de jogadores. Quanto maiores forem as verbas destinadas ao pagamento de altos salários, maior a probabilidade de contratação de bons jogadores, uma vez que, quanto melhor for o jogador, mais caro o seu salário. Com isso, inicia-se a criação de um elenco forte e competitivo. Esse elenco é capaz de vencer os jogos e as competições, alcançando assim o resultado esportivo.

Com a conquista de vitórias e, por consequência, campeonatos, há um aumento nas receitas, seja pelo prêmio da própria competição, seja pelo aumento da bilheteria ou pelo aumento de visibilidade e, consequentemente, patrocínio e cotas de transmissão televisiva. $\mathrm{O}$ aumento de receita gera o resultado financeiro e dá origem a um novo ciclo, uma vez que o mesmo comumente é reaplicado em contratações e salário de novos jogadores, visando ao resultado esportivo.

Ou seja, quanto maior for a riqueza de um clube, maior será a habilidade que este terá em gastar dinheiro e, por conseguinte, a probabilidade de ele ter um melhor resultado em campo é maior (BARAJAS; FERNÁNDEZ-JÁRDON; CROLLEY, 2005).

Os resultados financeiro e esportivo são complementares e, simultaneamente, distintos. Se focar unicamente em seu desempenho esportivo, um clube poderá gastar mais que o necessário, não gerando novas riquezas, e acabar por comprometer a saúde financeira da entidade no médio e longo prazo, acarretando dívidas e déficits. Em contrapartida, um clube que se preocupar exclusivamente com os resultados financeiros, pode optar por reduzir custos 
e, dessa forma, não ser capaz de criar equipes competitivas, não alcançando o desempenho esportivo. Nesse caso, a geração de riqueza também ficaria comprometida no longo prazo.

Equilibrar estes dois desempenhos, a fim de obter sucesso em ambos, não é uma tarefa simples, demandando, acima de tudo, uma gestão responsável e profissional, que atue da forma mais racional possível.

\subsection{A gestão do negócio futebol}

Historicamente, a gestão dos clubes de futebol no Brasil possui como característica mais marcante o amadorismo. No passado, não havia grande preocupação por parte dos dirigentes com a saúde financeira das entidades, sendo o foco quase exclusivamente montar elencos fortes para disputar as competições (LEONCINI; SILVA, 2005).

Atualmente, as entidades esportivas têm dado uma maior importância à parte administrativa. Porém, isso acontece muito lentamente. Mósca, Silva e Bastos (2009, p. 54) afirmam que "apenas nas últimas duas décadas encontram-se traços de administração profissional em alguns poucos clubes brasileiros".

Um dos fatores que podem justificar a dificuldade na gestão de algumas entidades esportivas é o aspecto passional existente nesse tipo de negócio, tendo em vista que a relação emocional com o futebol pode influenciar o comportamento dos gestores dos clubes na tomada de decisão (GUZMÁN; MORROW, 2007; REZENDE; DALMÁCIO; PEREIRA, 2010). Assim, o fator psicológico-emocional leva os gestores a tomar decisões considerando a emoção em detrimento da razão (PEREIRA et al., 2004, p. 2). Isso pode acarretar, por exemplo, uma contratação desnecessária, que pode comprometer as despesas salariais do clube e não levar a um retorno desejável. Isso é corroborado por Ferri et al. (2017), para quem os gestores do futebol podem decidir por algo irracional ou não útil para a equipe.

\subsection{Estudos anteriores}

Nos últimos 20 anos, as pesquisas com futebol, analisando os aspectos financeiros e econômicos se tornaram mais comuns, principalmente aquelas que fazem relação entre os resultados esportivos dos clubes e seu desempenho financeiro. 
Um dos estudos seminais é o de Szymanski (1998), que analisou 69 clubes do futebol inglês na temporada de 1996/1997. Como base para a pesquisa, o autor utilizou dois princípios: o melhor desempenho na liga gera maiores receitas; e o aumento nos gastos com salários leva a um melhor desempenho do campeonato. Através de regressão simples, o estudo verificou uma relação alta e positiva para os dois princípios. Dessa forma, o autor concluiu que há relação direta entre receitas e posição do clube no campeonato, bem como entre os gastos com salários e a posição do clube.

No Brasil, um dos primeiros estudos nesta temática foi o de Pereira et al. (2004), que verificaram a relação entre desempenhos esportivos e econômicos, representado pelo resultado operacional, de 16 clubes brasileiros que disputaram a liga nacional entre 2001 e 2002. Para isso, os autores utilizaram a análise do coeficiente de correlação de Spearman. Encontraram um "grau de correlação significativo entre as receitas e o desempenho em campo, o que comprova a hipótese de que desempenho financeiro é compatível com a performance esportiva" (PEREIRA et al., 2004, p. 13).

Barajas, Fernández-Járdon e Crolley (2005) testaram, através de regressões, a relação entre desempenho esportivo e resultados econômicos em clubes da Espanha, analisando 34 clubes, perfazendo uma amostra final de 134 observações, durante o período de 1998 a 2002. Como resultados, os autores ressaltam que o resultado esportivo afetou forte e positivamente a geração de receitas dos clubes de futebol. Porém, quando comparado com o lucro líquido, o desempenho esportivo não tem poder explicativo.

Göllü (2012) investigou o possível impacto do resultado financeiro no desempenho esportivo nos quatro grandes clubes de futebol da Turquia, durante o período de 2002 a 2009. O autor optou por realizar uma correlação de Spearman com estas variáveis e encontrou, como resultado, uma indicação de que não houve impacto dos resultados financeiros sobre o desempenho esportivo.

Dimitropoulos e Limperopoulos (2014) buscaram examinar a relação entre desempenho esportivo e financeiro, e como o investimento em jogadores impacta nessa relação nos clubes de futebol da Grécia, num período entre as temporadas de 2004/2005 e 2008/2009. Para cumprir com essa proposta, optaram por utilizar uma regressão com dados em painel, controlando os efeitos fixos. Como achado, destaca-se uma relação significante e negativa entre o resultado financeiro e o valor dos jogadores, indicando que a decisão de investimento em jogadores não 
se baseia em fatores econômicos, mas apenas esportivos. Além disso, mostra-se uma relação positiva entre investimentos em jogadores e resultados esportivos.

No Brasil, nota-se uma tendência aos estudos que abordam a eficiência econômica e esportiva, utilizando o método de Data Envelopment Analysis (DEA). Estudos como Nascimento et al. (2015), Dantas, Machado e Macedo (2015) e Freitas, Farias e Flach (2017) enveredaram por esta linha de pesquisa.

Nascimento et al. (2015) efetuaram uma análise da eficiência financeira dos clubes de futebol brasileiros no período de 2006 a 2011. O estudo utilizou como metodologia a DEA e uma correlação entre variáveis financeiras, econômicas e esportivas. Como resultados, encontraram uma relação positiva e significante entre eficiência financeira e esportiva, sugerindo ser possível alinhar estes interesses. Outro resultado interessante é a relação positiva entre custo do departamento de futebol e o desempenho esportivo, ou seja, quanto mais investimentos em contratações e salários de jogadores e comissão técnica, melhores resultados no campo de jogo.

Dantas, Machado e Macedo (2015) visaram avaliar quais eram os fatores determinantes da eficiência dos clubes de futebol no Brasil. Para isso, utilizaram dados de 36 clubes brasileiros de 2010 a 2012. Primeiramente, realizaram a DEA para encontrar o índice de eficiência e, em seguida, fizeram uma regressão para verificar quais fatores impactam na eficiência dos clubes. Como resultados, o estudo não apresentou relação significativa entre grau de endividamento e eficiência, tendo apenas as variáveis "títulos" e "divisão" se mostrado significativas e ambas positivas com relação à eficiência.

Freitas, Farias e Flach (2017) fizeram um estudo visando analisar a eficiência dos clubes brasileiros em gerar receitas e a razão por trás disso. Foram analisados dados de 25 clubes no ano de 2014, e a metodologia foi similar à aplicada por Dantas, Machado e Macedo (2015). Os resultados convergem para o estudo de Dantas, Machado e Macedo (2015), em que apenas as variáveis "títulos" e "divisão" foram estatisticamente significantes para a eficiência dos clubes.

Por fim, Ferri et al. (2017) investigaram a relação entre resultados financeiros e esportivos de clubes do futebol italiano. Para isso, utilizou regressão por dados em painel, com efeito fixo, com uma amostra com 29 clubes e 7 temporadas (2007/08 a 2013/14). Dentre os achados mais relevantes desta pesquisa, pode-se colocar a relação positiva e significativa entre o LN do ativo total do clube, o seu investimento e o grau de endividamento, com o seu 
desempenho esportivo, além de uma relação fortemente positiva e significativa entre a despesa com salários e o resultado do clube dentro de campo.

O Quadro 1 sintetiza os estudos anteriores, as características da amostra, técnicas e variáveis utilizadas por estes e seus principais achados.

Quadro 1 - Resumo das pesquisas anteriores

\begin{tabular}{|c|c|c|c|c|}
\hline Estudo & País & Amostra & Técnica & Principais Resultados \\
\hline $\begin{array}{l}\text { Szymanski } \\
\text { (1998) }\end{array}$ & Inglaterra & $\begin{array}{c}69 \\
\text { observações }\end{array}$ & $\begin{array}{l}\text { Regressão } \\
\text { Simples }\end{array}$ & $\begin{array}{l}\text { Relação direta entre receitas e a posição do } \\
\text { clube no campeonato, e dos gastos com salários } \\
\text { e a posição do clube. }\end{array}$ \\
\hline $\begin{array}{l}\text { Pereira et al. } \\
\quad(2004)\end{array}$ & Brasil & $\begin{array}{c}32 \\
\text { observações }\end{array}$ & $\begin{array}{l}\text { Correlação } \\
\text { de } \\
\text { Spearman }\end{array}$ & $\begin{array}{l}\text { Relação significativa entre receitas e } \\
\text { desempenho esportivo. }\end{array}$ \\
\hline $\begin{array}{c}\text { Barajas, } \\
\text { Fernández- } \\
\text { Járdon e } \\
\text { Crolley } \\
\text { (2005) }\end{array}$ & Espanha & $\begin{array}{c}134 \\
\text { observações }\end{array}$ & $\begin{array}{l}\text { Regressão } \\
\text { Simples }\end{array}$ & $\begin{array}{l}\text { Desempenho esportivo afeta forte e } \\
\text { positivamente a geração de receita dos clubes. O } \\
\text { desempenho esportivo não tem poder } \\
\text { explicativo sobre lucro líquido. }\end{array}$ \\
\hline Göllü (2012) & Turquia & $\begin{array}{c}32 \\
\text { observações }\end{array}$ & $\begin{array}{l}\text { Correlação } \\
\text { de } \\
\text { Spearman }\end{array}$ & $\begin{array}{l}\text { Indicação de que não houve impacto dos } \\
\text { resultados financeiros sobre o desempenho } \\
\text { esportivo. }\end{array}$ \\
\hline $\begin{array}{l}\text { Dimitropoulo } \\
\text { s e } \\
\text { Limperopoul } \\
\text { os (2014) }\end{array}$ & Grécia & $\begin{array}{c}100 \\
\text { observações }\end{array}$ & $\begin{array}{l}\text { Regressão } \\
\text { com Dados } \\
\text { em Painel }\end{array}$ & $\begin{array}{l}\text { Relação significante e negativa entre a } \\
\text { performance financeira e o valor dos jogadores. } \\
\text { Relação positiva entre investimentos em } \\
\text { jogadores e resultados esportivos. }\end{array}$ \\
\hline $\begin{array}{l}\text { Nascimento } \\
\text { et al. (2015) }\end{array}$ & Brasil & $\begin{array}{c}78 \\
\text { observações }\end{array}$ & $\begin{array}{c}\text { DEA e } \\
\text { Correlação }\end{array}$ & $\begin{array}{l}\text { Relação positiva e significante entre eficiência } \\
\text { financeira e esportiva. } \\
\text { Relação positiva entre custo do departamento do } \\
\text { futebol e o desempenho esportivo. }\end{array}$ \\
\hline $\begin{array}{l}\text { Dantas, } \\
\text { Machado e } \\
\text { Macedo } \\
\text { (2015) }\end{array}$ & Brasil & $\begin{array}{c}108 \\
\text { observações }\end{array}$ & $\begin{array}{l}\text { DEA e } \\
\text { Regressão } \\
\text { Tobit }\end{array}$ & $\begin{array}{l}\text { Não apresentou relação significativa entre grau } \\
\text { de endividamento e eficiência. } \\
\text { Títulos e divisão se mostraram significativas e } \\
\text { ambas positivas com relação à eficiência. }\end{array}$ \\
\hline $\begin{array}{l}\text { Freitas, } \\
\text { Farias e } \\
\text { Flach }(\mathbf{2 0 1 7})\end{array}$ & Brasil & $\begin{array}{c}25 \\
\text { observações }\end{array}$ & $\begin{array}{l}\text { DEA e } \\
\text { Regressão } \\
\text { Tobit }\end{array}$ & $\begin{array}{l}\text { Apenas as variáveis títulos e divisão foram } \\
\text { significantes para a eficiência dos clubes. }\end{array}$ \\
\hline $\begin{array}{l}\text { Ferri et al. } \\
\qquad(2017)\end{array}$ & Itália & $\begin{array}{c}203 \\
\text { observações }\end{array}$ & $\begin{array}{c}\text { Regressão } \\
\text { com Dados } \\
\text { em Painel }\end{array}$ & $\begin{array}{c}\text { Relação positiva e significativa entre o LN do } \\
\text { ativo total, seu investimento e GE, com o seu } \\
\text { desempenho esportivo. } \\
\text { Relação fortemente positiva entre despesa com } \\
\text { salários e desempenho esportivo } \\
\text { FCO teve impacto negativo no desempenho } \\
\text { esportivo. }\end{array}$ \\
\hline
\end{tabular}

Fonte: elaboração própria.

Com base nestes resultados e a fim de cumprir com os objetivos deste estudo, foram selecionadas variáveis a serem utilizadas neste estudo. A proxy escolhida e o comportamento esperado dessas variáveis serão explicados na metodologia. 


\section{METODOLOGIA}

\subsection{Tipologia, população e amostra}

De acordo com a tipologia elaborada por Raupp e Beuren (2006), pode-se caracterizar este estudo, quanto aos objetivos, como um estudo descritivo, uma vez que visa descrever o comportamento dos indicadores de desempenho financeiro e esportivo dos clubes de futebol do Brasil; documental, em relação aos procedimentos de pesquisa, com os dados coletados através de consulta aos relatórios contábeis dos clubes; e quanto à abordagem e tratamento dos dados, como quantitativo, visto que realiza tratamentos estatísticos para a coleta e análise de dados (RAUPP; BEUREN, 2006).

A população definida para o estudo são todos os clubes que participaram pelo menos uma vez de uma das duas principais divisões do Campeonato Brasileiro (Séries A e B, respectivamente primeira e segunda divisões) no período entre 2013 e 2016, totalizando 50 times. Destas entidades, foram coletadas as demonstrações contábeis - BP, DRE e NE publicadas para este período. As informações contábeis dos clubes foram buscadas, primeiramente, no website destas entidades. Caso não fossem encontradas, partia-se para uma busca na página eletrônica da Federação Estadual de Futebol a que a agremiação está vinculada.

A opção pelo corte temporal de 2013 em diante se deu pela promulgação da Resolução CFC n ${ }^{\circ}$ 1.429, de 25 de janeiro de 2013 (CFC, 2013), que modificou alguns critérios de mensuração, registro e evidenciação das informações contábeis dos clubes de futebol, visando a uma padronização das demonstrações contábeis.

Treze dos 50 clubes foram excluídos da amostra por não apresentarem as demonstrações contábeis para pelo menos 3 anos do período em análise. Além destes, o Oeste foi também retirado da amostra por julgamento dos autores, visto apresentar informações contábeis pouco confiáveis (como, por exemplo, o fato de que o único ativo do clube são as disponibilidades) as quais poderiam comprometer o resultado da pesquisa. Dessa forma, a amostra final foi composta por 36 clubes, totalizando 141 observações para análise estatística. O Quadro 2, a seguir, apresenta os clubes que compõem a amostra. 
DESEMPENHO ECONÔMICO-FINANCEIRO E DESEMPENHO ESPORTIVO: UMA ANÁLISE COM CLUBES DE FUTEBOL DO BRASIL

Quadro 2 - Clubes que integram a amostra

\begin{tabular}{|c|c|c|c|}
\hline \multicolumn{4}{|c|}{ Clubes } \\
\hline América/MG (AMG) & Ceará (CEA) & Goiás (GOI) & Portuguesa (POR) $* * *$ \\
\hline ASA (ASA) & Chapecoense $(\mathrm{CHA}) * *$ & Grêmio (GRE) & Santa Cruz (STA) \\
\hline Atlético/GO (AGO) & Corinthians (COR) & Internacional (INT) & Santos (SAN) \\
\hline Atlético/MG (ATM) & Coritiba (CTB) & Joinville (JOI) & São Caetano (SCA) \\
\hline Atlético/PR (ATP) & Criciúma (CRI) & Mogi Mirim (MOG) & São Paulo (SPA) \\
\hline Avaí (AVA) & Cruzeiro (CRU) & Náutico (NAU) & Sport Recife (SPO) \\
\hline Bahia (BAH) & Figueirense (FIG) & Palmeiras (PAL) & Vasco (VAS) \\
\hline Botafogo (BOT) & Flamengo (FLA) & Paysandu $(\mathrm{PAY})^{*}$ & Vila Nova/GO (VNG) \\
\hline Bragantino (BRA) & Fluminense (FLU) & Ponte Preta (PON) & Vitória (VIT) \\
\hline
\end{tabular}

Fonte: elaboração própria.

\subsection{Variáveis e modelos de análise}

Para atingir os objetivos propostos do trabalho, inicialmente se realizou uma análise descritiva dos dados coletados, a fim de examinar o comportamento dos resultados econômicos e financeiros dos clubes de futebol para o período em questão. Dessa forma, foi possível verificar a saúde administrativa das entidades que compõem a amostra, bem como investigar tendências de possíveis melhorias ou pioras na sua situação financeira ao longo do período. A análise descritiva dos dados foi executada com o software Excel@. Em seguida, realizou-se uma regressão com dados em painel, que oferece dados mais informativos, menos colinearidade entre variáveis e maior eficiência na estimação (GUJARATI; PORTER, 2011).

Para representar o desempenho esportivo dos clubes, variável dependente dos modelos, utilizou-se o Ranking de Clubes da CBF, representado na variável RankCBF, por se tratar de uma variável recorrentemente utilizada em pesquisas nacionais para representar o desempenho esportivo, como, por exemplo, em Silva (2013), Nascimento et al. (2015) e Freitas, Farias e Flach (2017). Este ranking considera o ano corrente e os quatro anteriores, dando pesos regressivos por proximidade temporal, ou seja, o ano corrente tem peso 5, o anterior tem peso 4 e assim sucessivamente.

Também se propôs utilizar a métrica de pontuação da CBF, considerando apenas o desempenho do clube ano corrente. Esta variável, chamada de RankCBF_Ano, foi elaborada pelos autores, considerando o método de cálculo do ranking de clubes da CBF e a participação 
e desempenho dos clubes da amostra nas competições nacionais e sul-americanas. O estudo de Dantas (2013) também utilizou esta métrica como proxy de desempenho esportivo.

Tanto o método de cálculo quanto a colocação das equipes nas competições nacionais foram buscadas na própria página eletrônica da CBF. Já as informações da participação e desempenho dos clubes nas competições sul-americanas foram coletadas no website da CONMEBOL.

Com relação às variáveis independentes, foram utilizados indicadores de desempenho econômico-financeiro. O Quadro 3 mostra os índices selecionados, pesquisas que utilizaram estes indicadores e o sinal esperado para eles.

Quadro 3 - Variáveis independentes utilizadas

\begin{tabular}{|c|c|c|c|}
\hline Variável & Descrição & Pesquisas Anteriores & $\begin{array}{l}\text { Sinal } \\
\text { esperado }\end{array}$ \\
\hline LN_Rec & $\begin{array}{l}\text { Logaritmo Natural da Receita Bruta } \\
\text { Total }\end{array}$ & $\begin{array}{l}\text { Szymanski (1998); Barajas, } \\
\text { Fernández-Járdon e Crolley (2005); } \\
\text { Ferri et al. (2017) }\end{array}$ & + \\
\hline LN_Desp & $\begin{array}{l}\text { Logaritmo Natural da Despesa com } \\
\text { Salários }\end{array}$ & Szymanski (1998); Ferri et al. (2017) & + \\
\hline End & $\begin{array}{l}\text { (Passivo Circ. + Passivo Não Circ.) / } \\
\text { Ativo total }\end{array}$ & $\begin{array}{l}\text { Göllü (2012); Dimitropoulos e } \\
\text { Limperopoulos }(2014) ; \quad \text { Dantas, } \\
\text { Machado e Macedo (2015); Ferri et al. } \\
\text { (2017). }\end{array}$ & + \\
\hline EBIT & $\begin{array}{l}\text { Resultado antes dos juros e impostos } \\
\text { sobre a renda }\end{array}$ & Teste da pesquisa & - \\
\hline AnoElei & $\begin{array}{l}\text { Dummy que verifica se o clube } \\
\text { passou por eleições presidenciais (1) } \\
\text { ou não (0) no ano em questão. }\end{array}$ & Göllü (2012) & - \\
\hline
\end{tabular}

Fonte: elaboração própria.

Sendo assim, os modelos de regressões propostos para tentar verificar a relação entre os resultados esportivos e financeiros ficam, assim, determinados:

$$
\begin{aligned}
& \operatorname{RankCBF}_{i t}=\beta_{0}+\beta_{1} L N_{-} \operatorname{Rec}_{i t}+\beta_{2} \text { End }_{i t}+\beta_{3} \text { EBIT }_{i t}+\beta_{4} \text { AnoElei }_{i t}+\varepsilon_{i t} \\
& \text { RankCBF_Ano }_{i t}=\beta_{0}+\beta_{1} L N_{-} \operatorname{Rec}_{i t}+\beta_{2} \text { End }_{i t}+\beta_{3} E_{B I T}+\beta_{4} \text { AnoElei }_{i t}+\varepsilon_{i t} \\
& \operatorname{RankCBF}_{i t}=\beta_{0}+\beta_{1} L N_{-} \text {DespSal }_{i t}+\beta_{2} \text { End }_{i t}+\beta_{3} \text { EBIT }_{i t}+\beta_{4} \text { AnoElei }_{i t}+\varepsilon_{i t}
\end{aligned}
$$

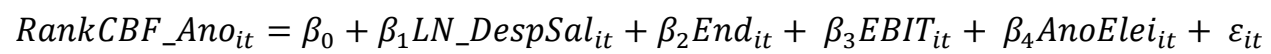

Onde:

RankCBF $F_{i t}$ : Pontuação do clube no Rankingde Clubes da CBF;

RankCBF_Ano ${ }_{i t}$ : Pontuação do clube no Ranking de Clubes da CBF, considerando apenas a pontuação do ano corrente;

$\beta_{0}$ : Termo constante; 
$\beta_{1} ; \beta_{2} ; \beta_{3} ; \beta_{4}$ : Coeficientes angulares das variáveis independentes;

$L N_{-} R e c_{i t}$ : Logaritmo natural da receita bruta total do clube;

$E n d_{i t}$ : Razão entre passivo total (passivo circulante + passivo não circulante) e ativo total;

$E B I T_{i t}$ : Resultado antes das despesas e receitas financeiras do exercício;

AnoElei $i_{i t}$ : Dummy para verificar se no ano em questão o clube passou por eleições para presidência (1) ou não $(0)$;

$L N_{-}$DespSal $\mathrm{it}_{\mathrm{it}}$ Logaritmo natural da despesa de salários do clube; $\mathrm{e}$

$\varepsilon_{i t}$ : Termo de erro da regressão.

Foram utilizadas as variáveis LN_Rec e LN_DespSal em modelos diferentes pois elas apresentaram alto índice de colinearidade (VIF > 5). Dessa forma, para não perder estas variáveis e nem enviesar os resultados do modelo, optou-se pela criação de mais duas equações de regressão (modelos 3 e 4), onde fosse possível testá-las, sem vieses ocasionados pela sua utilização conjunta.

A regressão com dados em painel pode ser realizada mediante três técnicas: Pooled, efeitos fixos (EF) e efeitos aleatórios (EA). A determinação de qual técnica se enquadra melhor para a amostra selecionada se dá através da ação combinada de três testes: Teste de Chow, Teste de Hausman e Teste LM de Breusch-Pagan. A Tabela 1 mostra o resultado destes testes para os quatro modelos utilizados.

Tabela 1 - Resultado dos testes de determinação do tipo de regressão

\begin{tabular}{lllll}
\hline \multirow{2}{*}{ Testes } & Modelo 1 & Modelo 2 & Modelo 3 & Modelo 4 \\
\cline { 2 - 5 } & p-valor & p-valor & p-valor & p-valor \\
\hline Chow & $<0,0001$ & $<0,0001$ & $<0,0001$ & $<0,0001$ \\
Breusch- & $<0,0001$ & $<0,0001$ & $<0,0001$ & $<0,0001$ \\
Pagan & $<0,0001$ & 0,0465 & 0,0004 & 0,0932 \\
Hausman & \multicolumn{4}{c}{ Fonte: elaboração própria. }
\end{tabular}

De acordo com os resultados dos testes, para os modelos 1, 2 e 3, o tipo de regressão com dados em painel mais adequado para este conjunto de dados é o que controla os efeitos fixos, ao nível de significância de 5\%. Já o modelo 4 apresentou a regressão com efeitos aleatórios mais oportuna a $5 \%$ e os efeitos fixos a $10 \%$. Contudo, para maior comparabilidade entre os resultados, procedeu-se à regressão com dados em painel com efeitos fixos para os quatro modelos. 
Foram testados, também, os pressupostos básicos para a realização de regressão: normalidade dos resíduos, homocedasticidade residual e não colinearidade das variáveis independentes. Para o pressuposto da normalidade, utilizou-se o teste Qui Quadrado $\left(\chi^{2}\right)$; para o pressuposto da homocedasticidade, o teste LM de White; e para medir a colinearidade, foi analisado o Variance Inflation Factor (VIF). A Tabela 2 elucida o resultado dos testes para os quatro modelos realizados. Todos estes testes foram rodados no software Gretl@.

Tabela 2 - Resultado dos testes de pressupostos

\begin{tabular}{lllll}
\hline \multirow{2}{*}{ Pressuposto } & Modelo 1 & Modelo 2 & Modelo 3 & Modelo 4 \\
\cline { 2 - 5 } & p-valor & p-valor & p-valor & p-valor \\
\hline Normalidade & 0,6859 & 0,0149 & 0,0933 & 0,0006 \\
Homocedasticidade & $<0,0001$ & $<0,0001$ & $<0,0001$ & $<0,0001$ \\
\hline Multicolinearidade & VIF & VIF & VIF & VIF \\
\hline Var & 1,242 & 1,242 & - & - \\
\hline LN_Rec & - & - & 1,112 & 1,112 \\
LN_DespSal & 1,062 & 1,062 & 1,038 & 1,038 \\
End & 1,188 & 1,188 & 1,081 & 1,081 \\
EBIT & 1,006 & 1,006 & 1,004 & 1,004 \\
AnoElei & \multicolumn{5}{l}{}
\end{tabular}

Nenhum dos modelos realizados apresentou problemas de multicolinearidade entre as variáveis independentes, atendendo a este pressuposto. Os quatro modelos apresentaram problemas com heterocedasticidade residual. Para minimizá-los, foram utilizados erros padrão robustos. Por fim, apenas os modelos 1 e 3 apresentaram normalidade dos resíduos, estando os demais com problemas de normalidade residual. Contudo, por se tratar de uma amostra grande (141 observações), sua distribuição tende à normalidade, de acordo com o Teorema do Limite Central. Dessa forma, pode-se relaxar o pressuposto da normalidade proceder à realização das regressões. Estas foram executadas com o software Gretl@.

Uma das limitações do estudo decorre do caráter não probabilístico da amostra: os clubes foram escolhidos por conveniência, e a pesquisa visou descrever o comportamento apenas deles, no período selecionado. O modelo é limitado, uma vez que não foram testados todos os indicadores financeiros existentes nem é possível afirmar que a regressão por dados em painel seja a melhor forma de verificar os impactos do resultado financeiro sobre o resultado esportivo. 


\section{APRESENTAÇÃO E ANÁLISE DOS RESULTADOS}

\subsection{Estatísticas descritivas das variáveis}

Conforme exposto, a primeira etapa de análise utilizada neste trabalho consiste em verificar as estatísticas descritivas das variáveis utilizadas no modelo de regressão. O Quadro 4 apresenta um resumo das estatísticas descritivas das variáveis para os quatro anos de análise.

Quadro 4 - Estatísticas descritivas das variáveis do estudo

\begin{tabular}{|c|c|c|c|c|c|}
\hline Variáveis & $\begin{array}{l}\text { Estatística } \\
\text { descritiva }\end{array}$ & 2013 & 2014 & 2015 & 2016 \\
\hline \multirow{5}{*}{ RankCBF } & Média & 9.114 & 8.661 & 8.616 & 8.556 \\
\hline & Mediana & 8.639 & 7.240 & 7.991 & 7.856 \\
\hline & Desv Pad & 4.228 & 4.011 & 3.921 & 3.952 \\
\hline & Mínimo & 890 (MOG) & 1.448 (MOG) & 2.186 (MOG) & $1.384(\mathrm{SCA})$ \\
\hline & Máximo & 15.286 (GRE) & $15.328(\mathrm{CRU})$ & 14.664 (COR) & 15.038 (GRE) \\
\hline \multirow{5}{*}{ RankCBF_Ano } & Média & 641 & 616 & 624 & 624 \\
\hline & Mediana & 551 & 511 & 518 & 532 \\
\hline & Desv Pad & 360 & 395 & 379 & 406 \\
\hline & Mínimo & 120 (MOG) & 116 (SCA) & $0(\mathrm{SCA})$ & $0(\mathrm{SCA})$ \\
\hline & Máximo & 1.490 (GRE) & $1.680(\mathrm{CRU})$ & 1.410 (SPA) & $1.600(\mathrm{PAL})$ \\
\hline \multirow{5}{*}{ Receita } & Média & 97.971 .520 & 90.732 .716 & 109.889 .411 & 143.957 .311 \\
\hline & Mediana & 49.052 .678 & 50.883 .221 & 53.032 .799 & 75.603 .540 \\
\hline & Desv Pad & 97.597 .631 & 91.691 .568 & 117.675 .118 & 148.318 .692 \\
\hline & Mínimo & $4.889 .742(\mathrm{VNG})$ & 3.959 .098 (ASA) & 3.940 .144 (ASA) & $2.107 .784(\mathrm{ASA})$ \\
\hline & Máximo & $\begin{array}{l}362.832 .000 \\
(\mathrm{SPA})\end{array}$ & $\begin{array}{l}347.027 .000 \\
(\text { FLA })\end{array}$ & $\begin{array}{l}363.829 .046 \\
(\mathrm{CRU})\end{array}$ & $\begin{array}{l}510.074 .000 \\
(\text { FLA })\end{array}$ \\
\hline \multirow{5}{*}{$\begin{array}{l}\text { Despesas com } \\
\text { Salários }\end{array}$} & Média & 42.294 .367 & 40.260 .879 & 44.959 .788 & 52.663 .527 \\
\hline & Mediana & 32.002 .020 & 26.642 .657 & 22.924 .328 & 31.440 .794 \\
\hline & Desv Pad & 36.411 .537 & 39.461 .595 & 46.167 .783 & 49.460 .219 \\
\hline & Mínimo & 318.537 (BRA) & 288.382 (BRA) & 162.876 (BRA) & 340.786 (BRA) \\
\hline & Máximo & $\begin{array}{l}120.844 .000 \\
\text { (SPA) }\end{array}$ & $\begin{array}{l}141.399 .742 \\
\text { (CRU) }\end{array}$ & $\begin{array}{l}192.157 .698 \\
\text { (CRU) }\end{array}$ & $\begin{array}{l}164.755 .432 \\
\text { (CRU) }\end{array}$ \\
\hline \multirow{5}{*}{ END } & Média & 1,7543 & 1,7435 & 1,7321 & 1,5748 \\
\hline & Mediana & 1,1175 & 1,2540 & 1,1682 & 1,1439 \\
\hline & Desv Pad & 1,7673 & 1,5659 & 1,5258 & 1,4855 \\
\hline & Mínimo & 0,3074 (CRI) & 0,3773 (CRI) & 0,2690 (PAY) & 0,2710 (PAY) \\
\hline & Máximo & 7,3176 (BAH) & 8,1588 (BOT) & 7,2179 (BOT) & 7,7617 (BOT) \\
\hline \multirow{5}{*}{ EBIT } & Média & -1.226 .451 & 1.727 .742 & 3.412 .514 & 25.627 .136 \\
\hline & Mediana & 382.129 & -391.465 & 811.989 & 7.367.472 \\
\hline & Desv Pad & 23.266 .727 & 35.953 .543 & 32.052 .615 & 42.791 .624 \\
\hline & Mínimo & $\begin{array}{l}-100.806 .000 \\
(\mathrm{BAH})\end{array}$ & $\begin{array}{l}-65.797 .000 \\
\text { (SPA) }\end{array}$ & $\begin{array}{l}-111.362 .000 \\
(\mathrm{POR})\end{array}$ & -7.550 .382 (NAU) \\
\hline & Máximo & $52.048 .000(\mathrm{BOT})$ & $\begin{array}{l}142.164 .000 \\
(\mathrm{BOT})\end{array}$ & $\begin{array}{l}102.714 .000 \\
\text { (FLA) }\end{array}$ & $\begin{array}{l}191.833 .000 \\
(\text { FLA })\end{array}$ \\
\hline
\end{tabular}


Olhando inicialmente para a receita bruta total dos clubes, pode-se ver confirmada a afirmação de diversos autores nacionais e internacionais, como Kern, Schwarzmann e Wiedenegger (2012) e Nascimento et al. (2015), de que, com o passar dos anos, os clubes têm se transformado cada vez mais em negócios capazes de gerar elevados montantes de recursos. Para o ano de 2016, os 36 clubes participantes deste estudo geraram, ao todo, mais de R\$ 5 bilhões de receita bruta total, quase o dobro do montante gerado em 2013 (R \$ 3,3 bilhões). A média de receita dos clubes também subiu, de cerca de R \$ 98 milhões em 2013 para mais de R\$ 143 milhões em 2016. Contudo, é possível verificar uma concentração de geração de receitas em poucos clubes. Em 2016, apenas 17 dos 36 clubes da amostra tiveram mais de $\mathrm{R}$ \$ 100 milhões em receitas e juntos somaram quase $\mathrm{R}$ 4,5 bilhões.

A média de despesas com salários de 2013 a 2016 aumentou em mais de R \$ 10 milhões, representando um aumento de quase 25\%. O desvio-padrão também aumentou consideravelmente ao longo destes anos, chegando a um desvio de quase R $\$ 50$ milhões sobre a média, indicando uma grande disparidade entre as despesas salariais dos clubes.

Analisando o EBIT dos clubes, também é possível notar uma evolução do ponto de vista administrativo. Pode-se verificar, no Quadro 4, que a média do EBIT das agremiações saiu do negativo, em 2013, para uma média acima de R \$ 25 milhões em 2016. Ainda neste último ano, 27 clubes alcançaram um EBIT positivo, o que representa $75 \%$ da amostra. Isso mostra que os clubes de futebol têm melhorado seus resultados operacionais, apontando para uma preocupação dos gestores com o desempenho econômico-financeiro destas entidades. Além disso, ao analisar o desvio-padrão desta variável, pode-se perceber uma grande dispersão entre os valores, devido ao fato de a amostra conter clubes de diferentes tamanhos.

O endividamento é outro indicador que apresenta melhorias na amostra ao longo dos anos, demonstrando uma sutil redução no nível de endividamento dos clubes brasileiros no período estudado. Em média, este indicador, calculado pela razão do capital de terceiros sobre ativo total da entidade, caiu em cerca de 0,18 de 2013 para 2016. Porém, seus números ainda são elevados: tanto a média quanto a mediana ficaram acima de 1 nos quatro anos analisados. Isso significa que a principal fonte de financiamento da maioria dos clubes ainda é o capital de terceiros de curto e longo prazo, chegando a ser maior que os ativos totais dos clubes.

Ao analisar as estatísticas descritivas dos indicadores financeiros, foi possível atender a um dos objetivos específicos da pesquisa: analisar o desempenho econômico e financeiro dos clubes de futebol brasileiro nos últimos quatro anos (2013 a 2016). De forma geral, as entidades 
do futebol do Brasil apresentaram melhorias nos seus indicadores financeiros, ainda que em alguns, como o endividamento, ainda não estejam em um ponto desejável. Também fica nítida na análise a disparidade entre os clubes de diferentes portes, de modo que clubes maiores e de maiores torcidas tendem a ter melhores resultados financeiros que os menores.

\subsection{Análises de regressão}

A segunda parte da análise consiste em examinar os modelos de regressão múltipla com dados em painel por efeitos fixos. Foram executados quatro modelos, apresentados na metodologia. Para reduzir a disparidade entre os valores de receita e despesa salarial, procedeuse à logaritmização destes.

Os autores optaram por não excluir outliers restantes, uma vez que a exclusão destes da amostra diminuiria consideravelmente o número de observações e causaria um desbalanceamento do painel, inviabilizando utilizar a regressão com dados em painel por efeito fixo.

As variáveis LN_Rec, nos modelos 1 e 2, e LN_DespSal, nos modelos 3 e 4, também se apresentam como variáveis de controle do efeito tamanho, pois quanto maior o clube, maiores tendem a ser sua receita arrecadada e seu gasto com despesa salarial.

\subsubsection{Resultados do Modelo 1}

A Tabela 3 elucida os resultados obtidos na regressão do modelo 1.

Tabela 3 - Resultados da regressão com efeitos fixos do modelo 1

\begin{tabular}{llll}
\hline & \multicolumn{3}{l}{ Estatística } \\
& Coef & $\mathbf{t}$ & p-valor \\
\hline Const & $-2962,02$ & $-0,5035$ & 0,6177 \\
LN_Rec & 628,449 & 1,9120 & 0,064 \\
END & 282,212 & 2,0190 & 0,0523 \\
& $-1,48 E-$ & & \\
EBIT & 07 & $-0,0363$ & 0,9712 \\
AnoElei & $-36,4569$ & $-0,2743$ & 0,7855
\end{tabular}

(CONTINUA) 
(CONTINUAÇÃO)

\begin{tabular}{|c|c|}
\hline Informações & o Modelo \\
\hline $\mathbf{R}^{2}$-within & 0,0636 \\
\hline $\begin{array}{l}\text { Estatística F } \\
\text { p-valor }\end{array}$ & 2,0335 \\
\hline modelo & 0,111 \\
\hline
\end{tabular}

O modelo como um todo não se apresentou significativo ao nível de 5\%, com p-valor de 0,111 , o que mostra não ser ele adequado. Assim, para analisar as variações da pontuação dos clubes analisados no ranking oficial da CBF, não foi apropriado combinar o logaritmo da receita bruta, o grau de endividamento, o EBIT e o fato de ser ou não ano eleitoral.

\subsubsection{Resultados do Modelo 2}

Tabela 4 - Resultados da regressão com efeitos fixos do modelo 2

\begin{tabular}{llll}
\hline & Coef & Estatística t & p-valor \\
\hline Const & $-1996,92$ & $-3,171$ & 0,0032 \\
LN_Rec & 140,008 & 3,97 & 0,0003 \\
END & 63,8947 & 2,652 & 0,0119 \\
EBIT & $1,16 E-06$ & 1,451 & 0,1556 \\
AnoElei & 12,2492 & 0,3557 & 0,7242 \\
\hline Informações do Modelo & & \\
\hline R'-within & 0,134 & \\
Estatística F & 6,59305 & \\
p-valor & 0,00045 & \\
\hline \multicolumn{5}{c}{ Fonte: elaboração própria. } \\
\end{tabular}

O modelo apresentado na Tabela 4 foi significativo ao nível de $1 \%$, mostrando-se adequado para a tarefa de explicar as variações ocorridas na pontuação do ranking de clubes considerando apenas o ano corrente. $\mathrm{O} \mathrm{R}^{2}$ do modelo foi de 0,134 , ou seja, o modelo apresenta um poder preditivo de $13,4 \%$.

A variável LN_Rec se mostrou significativa ao nível de $1 \%$. Ademais, teve coeficiente positivo, mostrando que o aumento da receita bruta impacta num aumento na pontuação do ranking anual. Sendo assim, apresentou uma relação positiva com a métrica de desempenho esportivo utilizada. O END se mostrou significativo ao nível de 5\%. Seu coeficiente também 
foi positivo, indicando que, quanto maior o endividamento do clube no futebol brasileiro, maior tende a ser o seu desempenho esportivo anual.

A variável EBIT não foi significativa ao nível de 5\%, indicando que, quando considerados os resultados esportivos anuais dos clubes de futebol, o EBIT não exerceu influência para a amostra e período analisados. O mesmo aconteceu com a dummy de ano eleitoral, o que contribui para a ideia de não haver relação entre o ano eleitoral do clube e seu desempenho esportivo anual.

\subsubsection{Resultados do Modelo 3}

Tabela 5 - Resultados da regressão com efeitos fixos do modelo 3

\begin{tabular}{llll}
\hline & Coef & Estatística t & p-valor \\
\hline Const & $-11569,2$ & $-2,23$ & 0,0323 \\
LN_DespSal & 1164,47 & 3,8460 & 0,0005 \\
END & 286,039 & 2,3810 & 0,0228 \\
EBIT & $-5,04 \mathrm{E}-08$ & $-0,0143$ & 0,9886 \\
AnoElei & 13,9732 & 0,1111 & 0,9121 \\
\hline Informações do Modelo & \\
\hline R $^{2}$-within & 0,1613 & \\
Estatística F & 4,5445 & \\
p-valor & 0,0046 & \\
\hline \multicolumn{5}{c}{ Fonte: elaboração própria. }
\end{tabular}

O modelo 3 foi significativo ao nível de 1\%, uma vez que o seu p-valor foi baixo, como pode ser visto na Tabela 5. Seu $\mathrm{R}^{2}$ foi 0,1613 , apresentando maior poder preditivo que os modelos anteriores. Ou seja, o presente modelo, utilizando as variáveis LN_DespSal, END, EBIT e AnoElei, é capaz de explicar cerca de 16,13\% da variação ocorrida na pontuação do ranking oficial da $\mathrm{CBF}$.

A variável de despesa com salários, logaritmizada, mostrou-se significativa também ao nível de $1 \%$. O seu coeficiente apresentou sinal positivo, ou seja, aumento nas despesas salariais do clube leva a um aumento de sua pontuação no ranking oficial da CBF. A variável do grau de endividamento se mostrou significativa ao nível de $5 \%$, tendo coeficiente positivo e indicando que, quanto maior o endividamento do clube, maior a sua pontuação no ranking da $\mathrm{CBF}$, que considera os cinco últimos anos com pesos gradativos.

No que diz respeito ao EBIT, tal qual ocorrido nos dois modelos anteriores, esta variável não se mostrou significativa. O mesmo ocorre na dummy para o ano eleitoral, que também não 
foi significativa. Ambas as variáveis apresentaram p-valor bem elevados no modelo, maiores que 0,9 .

\subsubsection{Resultados do Modelo 4}

Tabela 6 - Resultados da regressão com efeitos fixos do modelo 4

\begin{tabular}{llll}
\hline & Coef & Estatística t & p-valor \\
\hline Const & $-2387,43$ & $-3,412$ & 0,0016 \\
LN_DespSal & 170,218 & 4,261 & 0,0001 \\
END & 59,2403 & 2,627 & 0,0127 \\
EBIT & $1,35 E-06$ & 1,981 & 0,0555 \\
AnoElei & 19,3183 & 0,564 & 0,5764 \\
\hline Informações do Modelo & \\
R $^{2}$-within & 0,1572 & \\
Estatística F & 5,21519 \\
p-valor & 0,0021 & \\
\hline \multicolumn{5}{c}{ Fonte: elaboração própria. }
\end{tabular}

Como se pode observar na Tabela 6 , o modelo foi significativo ao nível de $1 \%$. O R $\mathrm{R}^{2}$ da regressão foi de 0,1572 , mostrando que o modelo 4 explica $15,72 \%$ das variações ocorridas na pontuação de clubes que considera apenas o ano corrente.

A grande novidade deste modelo está na variável EBIT, significativa ao nível de $10 \%$, diferentemente das outras três regressões, em que não havia sido significante em nenhum dos três níveis. Seu coeficiente foi positivo, mostrando que aumentos no lucro antes do resultado financeiro e impostos acarretam um aumento na pontuação do ranking anual do clube. Esse resultado contraria as expectativas de que o EBIT poderia impactar negativamente o desempenho dos clubes.

A variável LN_DespSal apresenta coeficiente positivo, indicando que, quanto maior a despesa com salários do time, maior o seu desempenho esportivo. Além disso, esta foi significativa ao nível de $1 \%$. A variável END foi significante ao nível de $5 \%$ e com coeficiente positivo, apontado para a lógica de que, quanto maior o endividamento do clube, maior o seu desempenho esportivo no curto prazo.

Por fim, pode-se verificar que a dummy AnoElei não foi significativa também neste modelo. Dessa forma, é possível afirmar que, para a presente amostra, o ano em que ocorrem eleições no clube não impacta no desempenho esportivo do mesmo. 
Para a melhor discussão dos resultados encontrados nesta pesquisa, o Quadro 5 resume os achados, relacionando-os com os sinais esperados no desenvolvimento do estudo.

Quadro 5 - Resumo dos resultados encontrados

\begin{tabular}{|l|l|l|l|l|l|l|}
\hline $\begin{array}{l}\text { Variáveis } \\
\text { Relacionadas }\end{array}$ & $\begin{array}{l}\text { Sinal } \\
\text { Esperado }\end{array}$ & Modelo 1 & Modelo 2 & Modelo 3 & Modelo 4 & Conclusão \\
\hline LN_Rec & + & $\begin{array}{l}\text { Não } \\
\text { Significativo }\end{array}$ & + & $X$ & $X$ & Confirmado \\
\hline END & + & $\begin{array}{l}\text { Não } \\
\text { Significativo }\end{array}$ & + & + & + & Confirmado \\
\hline EBIT & - & $\begin{array}{l}\text { Não } \\
\text { Significativo }\end{array}$ & $\begin{array}{l}\text { Não } \\
\text { Significativo }\end{array}$ & $\begin{array}{l}\text { Não } \\
\text { Significativo }\end{array}$ & + & $\begin{array}{l}\text { Não } \\
\text { Confirmado }\end{array}$ \\
\hline LN_DespSal & + & X & $X$ & + & + & Confirmado \\
\hline AnoElei & - & $\begin{array}{l}\text { Não } \\
\text { Significativo }\end{array}$ & $\begin{array}{l}\text { Não } \\
\text { Significativo }\end{array}$ & $\begin{array}{l}\text { Não } \\
\text { Significativo }\end{array}$ & $\begin{array}{l}\text { Não } \\
\text { Significativo }\end{array}$ & $\begin{array}{l}\text { Não } \\
\text { Confirmado }\end{array}$ \\
\hline
\end{tabular}

Fonte: elaboração própria.

Conforme pode ser observado no Quadro 5, das cinco variáveis utilizadas no estudo, LN_Rec, END e LN_DespSal apresentaram sinal tal qual o esperado. A variável EBIT não foi significante nos modelos 1,2 e 3 e, no modelo 4, teve sinal inverso ao esperado, indicando que o EBIT impactaria positivamente no resultado esportivo dos clubes. Já a dummy AnoElei não foi significante em nenhum dos quatro modelos realizados.

A variável LN_Rec foi significante e positiva no modelo 2, sinalizando que, quanto maior a receita do clube, maior tende a ser o seu resultado esportivo. Esse resultado corrobora os achados de Szymanski (1998), Barajas, Fernández-Járdon e Crolley (2005) e Ferri et al. (2017). No modelo 1, a LN_Rec também foi positiva, mas o modelo em si não foi estatisticamente significante.

O endividamento, representado pela variável END, foi significante em todos os modelos realizados, que foram significativos, apresentando sinal positivo. Isso significa que, quanto maior o endividamento do clube, melhor seu resultado esportivo. Esse achado contradiz os resultados de Göllü (2012), Dimitropoulos e Limperopoulos (2014), Dantas, Machado e Macedo (2015), que encontraram que o grau de endividamento não tem significância para explicar a eficiência esportiva, mas corrobora os achados de Ferri et al. (2017).

Olhando para a despesa com salários, representado pela variável LN_DespSal, esta foi significativa em ambos os modelos que utilizaram este regressor, apresentando sinal positivo, tal qual esperado, indicando que, quanto maiores os gastos com salários dos clubes brasileiros, 
maior o desempenho dos clubes nas competições disputadas. Este resultado converge com os achados de Szymanski (1998), Dimitropoulos e Limperopoulos (2014) e Ferri et al. (2017) que, em diferentes países, encontraram também relação positiva entre gasto com jogadores e desempenho esportivo.

Considerando que as variáveis LN_Rec e LN_DespSal podem ser utilizadas ao tratar o efeito do tamanho dos clubes, este apresentou - em todos os modelos significativos - uma relação positiva com o desempenho esportivo, mostrando que, quanto maior o tamanho do clube, maior tende a ser o seu resultado esportivo.

As variáveis independentes combinadas foram mais eficientes para explicar a variação no desempenho esportivo quando este foi representado pelo ranking anual de desempenho esportivo elaborado pelos autores, sendo significativo nos 2 modelos com essa métrica, enquanto nos modelos que utilizam o Ranking oficial da CBF como indicador de desempenho esportivo, apenas o modelo 3 foi significativo. Isso mostra que os indicadores financeiros explicam melhor o ranking que considera apenas a temporada atual.

Outro ponto interessante para análise é que os modelos 3 e 4, que continham a variável LN_DespSal como regressor, tiveram um $\mathrm{R}^{2}$-within pouco maior que nos modelos que utilizava LN_Rec no lugar da despesa com salários. Sendo assim, há um indicativo de que o gasto com salários da equipe explica melhor o desempenho esportivo dos clubes do que o montante de receita que as entidades geram ao longo da temporada.

\section{CONSIDERAÇÕES FINAIS}

A presente pesquisa buscou analisar como os resultados econômicos e financeiros impactam o desempenho esportivo dos clubes das Séries A e B do futebol brasileiro. De maneira específica, buscava-se também analisar os desempenhos esportivos e financeiros dos clubes de futebol do Brasil.

Para encontrar os indicadores financeiros, foram coletados BP, DRE e NE dos clubes referente aos anos de 2013 a 2016. O recorte dado de 2013 em diante se deve pela promulgação da Resolução CFC no 1.429 de 2013, que alterou procedimentos de reconhecimento, mensuração e registro dos fatos contábeis. O desempenho esportivo foi medido com duas diferentes métricas: a pontuação do Ranking Nacional de Clubes, divulgado anualmente pela 
$\mathrm{CBF}$, e uma pontuação alternativa, também baseada nesse ranking da $\mathrm{CBF}$, mas considerando apenas os resultados do ano corrente.

A amostra compôs-se dos clubes brasileiros que participaram pelo menos uma vez do Campeonato Brasileiro Séries A ou B no período entre 2013 e 2016 e que apresentaram demonstrações contábeis em pelo menos três anos do período em questão, totalizando 36 clubes e 141 observações. As estatísticas descritivas da amostra apontaram que os clubes do futebol brasileiro têm evoluído no quesito financeiro, obtendo melhores resultados nos últimos anos. As receitas vêm aumentando ao longo dos anos, bem como o EBIT dos clubes. Contudo, os melhores resultados se concentraram em poucos times: aqueles considerados grandes, que possuem maior torcida e maior visibilidade. Um grande destaque nas características financeiras é o Flamengo, figurando entre as maiores receitas e maiores EBIT nos anos analisados. Corinthians, Palmeiras, São Paulo, Cruzeiro e Atlético-MG também foram clubes que tiveram altíssima arrecadação de recursos no período analisado. As entidades esportivas ainda se mostraram com índices de endividamento superiores a 1,5 para os quatro anos estudados, porém houve uma leve redução nesse quesito de 2013 a 2016.

Os investimentos em salários dos times também vêm aumentando ao longo dos últimos quatro anos: mais clubes têm gastado cifras que ultrapassam a casa de $\mathrm{R} \$ 100$ milhões com esse tipo de despesa. Tal resultado pode ter sido influenciado pela ideia de que melhores jogadores ganham maiores salários e trazem maior possibilidade de bons resultados esportivos. $\mathrm{O}$ Cruzeiro foi o clube que mais gastou com salários ao longo do período analisado, investindo cerca de R \$ 610 milhões no total. São Paulo, Internacional, Flamengo e Corinthians também foram clubes que gastaram grande montante de recursos ao longo dos 4 anos em análise, passando de $\mathrm{R} \$ 400$ milhões.

A receita bruta total, a despesa com salários e o grau de endividamento foram significativos, com sinal positivo, em todos os modelos significantes, confirmando o comportamento esperado para tais variáveis. O resultado da receita bruta converge com outras pesquisas, como Szymanski (1998), Barajas, Fernández-Járdon e Crolley (2005) e Ferri et al. (2017). Já o resultado da variável despesa com salários é convergente com Dimitropoulos e Limperopoulos (2014) e Ferri et al. (2017).

O resultado encontrado para a variável grau de endividamento corrobora os achados de Ferri et al. (2017) e contraria os de Dimitropoulos e Limperopoulos (2014), Dantas, Machado e Macedo (2015) e Freitas, Farias e Flach (2017). Isso pode dever-se à diferença da proxy 
utilizada, dado que a presente pesquisa utilizou os rankings da $\mathrm{CBF}$, enquanto a dos outros autores nacionais usaram um indicador de eficiência esportiva, encontrado através da Análise Envoltória de Dados.

O EBIT não se mostrou significativo em três dos quatro modelos realizados. No único que apresentou resultados significantes, apenas a 10\%, o sinal foi positivo, contrariamente ao esperado. Isso pode explicar-se pelo fato de que os clubes no Brasil são, em sua grande maioria, associações sem fins lucrativos, que não visam ao resultado financeiro (lucro/superávit), normalmente reaplicando seus proventos na manutenção ou expansão das atividades esportivas.

$\mathrm{O}$ ano eleitoral também não foi significante em nenhum dos modelos realizados, apontando que o desempenho esportivo do clube não é impactado pelo imbróglio da eleição presidencial da entidade.

Assim, os resultados apontaram para uma relação entre o desempenho esportivo e o financeiro. Os clubes preocupados não exclusivamente com resultado esportivo, mas também com uma boa gestão dos recursos financeiros tendem a ter melhores resultados nas competições disputadas.

É importante ressaltar que isso não significa que clubes com boa gestão financeira necessariamente vão ter bons resultados esportivos, uma vez que uma prática esportiva depende de fatores não financeiros, como os treinamentos, o desempenho dos jogadores, o calendário, dentre outros. Contudo, o desempenho econômico e financeiro é um meio para buscar melhorias no desempenho esportivo, como os resultados desta pesquisa indicaram.

Os resultados obtidos na presente pesquisa colaboram com o arcabouço científico dos estudos nesta área, uma vez que ainda não é absoluto o entendimento da literatura sobre a relação entre desempenho esportivo e financeiro. Também é de serventia aos times de futebol e ao público em geral, ao apontar para a importância de os clubes aumentarem sua preocupação com suas características econômicas e financeiras.

Uma das limitações do presente estudo foi o modelo estatístico utilizado, visto ele não garantir a melhor verificação possível entre a relação entre os desempenhos esportivos e financeiros. Além disso, a amostra contou com apenas 141 observações, devido à não divulgação dos relatórios financeiros de alguns clubes. Para pesquisas futuras, sugere-se ampliar o período de análise, inserindo as futuras demonstrações contábeis a serem publicadas para os próximos anos, além de experimentar outras metodologias, a fim de confirmar ou 
contestar os resultados apresentados. Além disso, pode-se fazer a mesma pesquisa com outros indicadores financeiros ou em outros países para verificar se o resultado se repete.

\section{REFERÊNCIAS}

BARAJAS, A.; FERNÁNDEZ-JÁRDON, C.; CROLLEY, L. Does sports performance influence revenues and economic results in spanish football? Munich Personal RePEc Archive, n. 3.234, p. 1-19, 2005.

BARONCELLI, A.; LAGO, U. Italian Football. Journal of Sports Economics, v. 7, n. 1, p. 13-28, fev. 2006.

BARROS, C. P.; ASSAF, A. G.; ARAUJO, A. F. Cost performance of Brazilian soccer clubs: A Bayesian varying efficiency distribution model. Economic Modelling, v. 28, n. 6, p. 27302735, 2011.

BENIN, M. M. Eficiência econômica em clubes de futebol: um estudo com base na análise envoltória de dados. 2017. 73 f. Dissertação (Mestrado em Ciências Contábeis) - Universidade do Vale do Rio dos Sinos, São Leopoldo-RS, 2017.

CFC - CONSELHO FEDERAL DE CONTABILIDADE. Resolução $\mathrm{n}^{\circ} 1.429$ de 2013. Aprova a ITG 2003 - Entidade Desportiva Profissional. Disponível em: <www.cfc.org.br/sisweb/sre/docs/RES_1429.doc>. Acesso em: 18 dez. 2016.

DANTAS, M. G. S. Fatores determinantes da eficiência financeira e esportiva de clubes de futebol do Brasil. 2013. 95 f. Dissertação (Mestrado em Ciências Contábeis) - Programa Multi-institucionale Inter-regional de Pós-Graduação em Ciências Contábeis, UnB/UFPB/UFRN 2013.

; BOENTE, D. R. A eficiência financeira e esportiva dos maiores clubes de futebol europeus utilizando de Análise Envoltória de Dados. Revista de Contabilidade e Organizações - RCO, Ribeirão Preto, v. 5, n. 13, p. 75-90, set./dez. 2011.

; MACHADO, M. A. V.; MACEDO, M. Á. DA S. Fatores determinantes da eficiência dos clubes de futebol do Brasil. Advances in Scientific and Applied Accounting, São Paulo, v. 8, n. 1, p. 113-132, jan./abr. 2015.

DIMITROPOULOS, P. E.; LIMPEROPOULOS, V. Player contracts, athletic and financial performance of the Greek football clubs. Global Business and Economics Review, v. 16, n. 
2, p. 123-141, 2014.

ESPITIA-ESCUER, M.; GARCÍA-CEBRIÁN, L. I. Measurement of the efficiency of football teams in the Champions League. Managerial and Decision Economics, v. 31, p. 373-386, 2010 .

FERRI, L.; MACCHIONI, R.; MAFFEI, M.; ZAMPELLA, A. Financial versus sports performance: The missing link. International Journal of Business and Management, v. 12, n. 3, p. 36-48, 2017.

FIGUEIREDO, G. H.; SANTOS, V.; CUNHA, P. R. Práticas de evidenciação em entidades desportivas: Um estudo nos clubes das Séries "A" e "B" do Campeonato Brasileiro de Futebol no período de 2011 a 2013. In: IX CONGRESSO ANPCONT, 9., 2015, Curitiba. Anais... São Paulo: AnpCont, 2015.

FREITAS, M. M.; FARIAS, R. A. S.; FLACH, L. Efficiency determinants in Brazilian football clubs. Brazilian Business Review, v. Especial, n. 1, p. 1-23, 2017.

GÖLLÜ, E. Impact of the financial performances of incorporations of football clubs in the domestic league on their sportive performances: A study covering four major football clubs in Turkey. Pamukkale Journal of Sport Sciences, v. 3, n. 1, p. 20-29, 2012.

GUJARATI, D. N.; PORTER, D. C. Econometria Básica. 5. ed. Porto Alegre: AMGH, 2011.

GUZMÁN, I. Measuring Efficiency and Sustainable Growth in Spanish Football Teams. European Sport Management Quarterly, v. 6, n. 3, p. 267-287, 2006.

; MORROW, S. Measuring efficiency and productivity in professional football teams: Evidence from the English Premier League. Central European Journal of Operations Research, v. 15, n. 4, p. 309-328, 2007.

HOFFMANN, R.; GING, L. C.; RAMASAMY, B. The Socio-Economic Determinants of International Soccer Performance. Journal of Applied Economics, v. V, n. 2, p. 253-272, 2002.

KERN, A.; SCHWARZMANN, M.; WIEDENEGGER, A. Measuring the efficiency of English Premier League football: A two-stage data envelopment analysis approach. Sport, Business and Management: An International Journal, v. 2, n. 3, p. 177-195, 2012. 
LEONCINI, M. P.; DA SILVA, M. T. Entendendo o futebol como um negócio: Um estudo exploratório. Revista Gestão \& Produção, v. 12, n. 1, p. 11-23, jan./abr. 2005.

MÓSCA, H. M. B.; SILVA, J. R. G. da; BASTOS, S. A. P. Fatores institucionais e organizacionais que afetam a gestão profissional de departamentos de futebol dos clubes: $\mathrm{O}$ caso dos clubes de dutebol no Brasil. Revista Gestão e Planejamento, v. 10, n. 1, p. 53-71, jan./jul. 2009.

NASCIMENTO, J. C. H. B.; NOSSA, V.; BERNARDES, J. R.; SOUSA, W. D. A eficiência dos maiores clubes de futebol brasileiros: Evidências de uma análise longitudinal no período de 2006 a 2011. Revista Contabilidade Vista \& Revista, Belo Horizonte, v. 26, n. 2, p. 137 161, maio/ago. 2015.

PEREIRA, A. G. C.; BRUNOZI JUNIOR, A. C.; KRONBAUER, C. A.; ABRANTES, L. A. Eficiência técnica e desempenho econômico-financeiro dos clubes de futebol brasileiros. REUNA, v. 20, n. 2, p. 115-138, 2015.

PEREIRA, C. A.; REZENDE, A. J.; CORRAR, L. J.; LIMA, E. M. A gestão estratégica de clubes de futebol: uma análise da correlação entre performance esportiva e resultado operacional. In: IV CONGRESSO USP DE CONTROLADORIA E CONTABILIDADE. Anais... São Paulo: USP, 2004.

RAUPP, F. M.; BEUREN, I. M. Metodologia da pesquisa aplicável as ciências sociais. In: BEUREN, I. M. et al. Como elaborar trabalhos monográficos em contabilidade: teoria e prática. 3. ed. São Paulo: Atlas, 2006. p. 46-97.

REZENDE, A. J.; CUSTÓDIO, R. dos S. Uma análise da evidenciação dos direitos federativos nas demonstrações contábeis dos clubes de futebol brasileiros. Revista de Educação e Pesquisa em Contabilidade (REPeC), Brasília, v. 6, n. 3, p. 229-245, jul./set. 2012.

; DALMÁCIO, F. Z.; PEREIRA, C. A. A gestão de contratos de jogadores de futebol: uma análise sob a perspectiva da teoria da agência - o caso do Clube Atlético Paranaense. Revista de Contabilidade e Controladoria, Curitiba, v. 2, n. 3, p. 95-123, set./dez. 2010.

SILVA, D. T. Determinantes de divulgação de ativos intangíveis: estudo do CPC 04 em clubes de futebol brasileiros. 2013. 127 f. Dissertação (Mestrado em Ciências Contábeis) Universidade Federal do Rio de Janeiro, Rio de Janeiro, 2013.

SZYMANSKI, S. Why is Manchester United so successful? Business Strategy Review, v. 9, n. 4, p. 47-54, 1998. 